\title{
EDITORIAL
}

\section{A REVIEW OF REVIEWING}

Without gall and like Gaul, all book reviewing is or should be divided into three parts. Part one states a clear and fair synopsis of the author's thesis, its significance, the method and sources used, and the newness and utility of the book's contribution. Part two sets forth a friendly inquiry into each of those points and highlights flaws and strengths discerned by the reviewer. Part three is a platform on which the reviewer constructs suggestions for ongoing examination by the author, other writers, or the reviewer.

In many publications and journals, at least one of these parts is either omitted or presented hypercritically and, alas, sometimes hypocritically. This negativism and failure in honesty is germinated and cultivated by multiple psychological, social, and academic factors which are systemic to the present status of scholarly writing and reviewing. The problem in academe is a misunderstanding of the coordinate functions of teaching and writing. Reputedly, some teachers like the Buddha and Socrates wrote nothing and insisted by their questions that education is primarily self-generated. Other educators like Jesus wrote only in sand. Although they never published, their words have not perished. Some modern professors either publish excessively-never an unpublished thought—or incessantly and quite lucratively, they republish variations of the same regurgitated ideas.

As a result many persons suffer: the writing professors, their students, their colleagues, and readers, all of whose time they both waste and steal. Further, aspiring authors with something new to express are kept out of a publishing market overcrowded with the same old good buddies caught up in clubbish conversation with themselves and their cronies. Living by the club, they perish by it. So do the many others whom they exclude from their cliques.

No wonder that aspiring authors and academics become infected with similar life-denying afflictions of mind and psyche and that a large portion of their book reviews gallicly ignore part one, what the author stated. Instead, they focus on part two, critical inquiry, in a spirit of the grand inquisition, intimidating many others who are interested in proposing thoughts for public discussion. These inquisitors then conclude with part three, turning new and constructive spin-offs into a narcissistic furthering of their own reflections. They complement their own careers by criticizing, carping, and living off the backs of others. Instead of acting and thinking their own thoughts, they simply react parasitically and in imitation of predecessors who have given bad examples.

The flaws in today's reviewing process, therefore, are endemic to existing academic structures. Worse, those defects injure and diminish 
many of us psychologically, socially, and spiritually. A constructive, compassionate, and life-affirming solution to the problem is to restore all three parts to which reviewing should be dedicated.

The reviewing process affects not only books but also proposals for public policy, funding, and educational and economic programs. Reviewing succeeds in those sectors as well as in bureaucracies (political, economic, religious, or academic) when the reviews do not proceed in circular bureaucratic fashions, but with minds and hearts courageously open to the outside, fresh air of new ideas and new life. Reviewers of books are, like all reviewers, charged not with a private enterprise, but with a public trust. To build, rebuild, and expand this crumbled trust, reviewers need always to review their own approach to reviewing, just as reformers of any organization stand in constant need of reformation.

As a public trust of all peoples, reviewing is too important to be relegated to professional reviewers who are out of touch with the recurring weaknesses and wisdom in popular perceptions.

One may pause on the subject for now by paraphrasing the conclusion of the Communist Manifesto: as ruling reviewers themselves pass in review, let them tremble at a revolution in reviewing. The public has nothing to lose but its chains. They have a world to gain. Reviewers of all kinds unite in the truth that will make you free!

-RODERICK HINDERY 